UDK 958.22

\title{
ASSESSMENT OF MARINE GEOID MODELS BY SHIP-BORNE GNSS PROFILES
}

\author{
Sander VARBLA ${ }^{1}$, Artu ELLMANN ${ }^{2}$, Silja MÄRDLA ${ }^{3}$, Anti GRUNO ${ }^{4}$ \\ 1, 2, ${ }^{3}$ Department of Civil Engineering and Architecture, Tallinn University of Technology, \\ Ehitajate tee 5, 19086 Tallinn, Estonia \\ ${ }^{4}$ Estonian Land Board, Mustamäe tee 51, 10621 Tallinn, Estonia \\ E-mails: ${ }^{1}$ sander.varbla@ttu.ee (corresponding author); ${ }^{2}$ artu.ellmann@ttu.ee; \\ 3silja.mardla@ttu.ee; ${ }^{4}$ anti.gruno@maaamet.ee
}

Received 21 April 2017; accepted 10 May 2017

\begin{abstract}
Even though the entire Baltic Sea is included in previous geoid modelling projects such as the NKG2015 and EGG07, the accuracy of contemporary geoid models over marine areas remains unknown, presumably being offshore around $15-20 \mathrm{~cm}$. An important part of the international cooperation project FAMOS (Finalising Surveys for the Baltic Motorways of the Sea) efforts is conducting new marine gravity observations for improving gravimetric quasigeoid modelling. New data is essential to the project as the existing gravimetric data over some regions of the Baltic Sea may be inaccurate and insufficiently scarce for the purpose of $5 \mathrm{~cm}$ accuracy geoid modelling. Therefore, it is important to evaluate geoid modelling outcome by independent data, for instance by shipborne GNSS measurements. Accordingly, this study presents results of the ship-borne marine gravity and GNSS campaign held on board the Estonian Maritime Administration survey vessel "Jakob Prei" in West-Estonian archipelago in June/July 2016. Emphasis of the study is on principles of using the GNSS profiles for validation of existing geoid models, post-processing of GNSS raw data and low-pass filtering of the GNSS results. Improvements in geoid modelling using new gravimetric data are also discussed. For example, accuracy of geoid models including the new marine gravity data increased $11 \mathrm{~mm}$ as assessed from GNSS profiles. It is concluded that the marine GNSS profiles have a potential in providing complementary constraints in problematic geoid modelling areas.
\end{abstract}

Keywords: ship-borne GNSS, marine gravimetry, sea surface topography, FAMOS, Baltic Sea.

\section{Introduction}

An international cooperation project FAMOS (Finalising Surveys for the Baltic Motorways of the Sea) has been initiated to improve the gravimetric quasigeoid model that will be needed for the realisation of the Baltic Sea Chart Datum 2000 (BSCD2000) as the new common height reference system for the Baltic Sea hydrographic surveying and nautical charts (FAMOS 2017). The goal is to improve the accuracy of GNSS (Global Navigation Satellite System) supported bathymetric measurements and navigation by computing a new $5 \mathrm{~cm}$ accuracy marine geoid (note that over marine areas the quasigeoid coincides with the geoid, thus for brevity the shorter term will often be used in the text) model over the entire Baltic Sea.
The existing gravimetric data over some regions of the Baltic Sea appear to be too sparse and inaccurate for the purpose of $5 \mathrm{~cm}$ geoid modelling (FAMOS 2017). It is estimated that the accuracy of contemporary geoid models over marine areas could often be no better than $15-20 \mathrm{~cm}$, especially in the gravity data void areas. For instance, some earlier studies have indicated that the precision of geoid models in coastal areas can suffer due to heterogeneity of regional gravity data (Liibusk, Ellmann 2015; Märdla et al. 2017). This could also yield systematic offsets in marine geoid models over certain marine areas (Ellmann 2010).

External verification is thus needed for validating the accuracy of geoid models. On land, geoid models are customarily evaluated by using precise GNSSlevelling points, whereas offshore such control points 
cannot be established. Instead, marine geoid models can be assessed by ship-borne GNSS measurements. For instance, the NKG04 gravimetric geoid model (Forsberg et al. 2004) was assessed by Jürgenson et al. (2008). Another similar experiment was carried out between 2011 and 2015 along Israeli coast (Lavrov et al. 2016). The purpose of the study was to determine suitability of ship-borne GNSS measurements for complementing geoid modelling. Results showed indeed, that the data obtained were sufficiently accurate for fulfil this task.

Different approaches have been tested in the region of interest of the present study - the Baltic Sea. In 2013, during gravity surveys on ice, GNSS data-points were acquired to determine geoidal heights (Märdla et al. 2015), see also a study by Liibusk et al. (2014). The results showed that high accuracy GNSS positioning on the sea ice possesses a potential for enhancing geoid modelling results. Airborne laser scanning measurements (in conjunction with GNSS-IMU trajectory computations) in 2012 demonstrated further possibilities for determining sea surface heights (Gruno et al. 2013) and subsequent validation of marine geoid models.

The present study also aims at assessing improvements in geoid models due to inclusion of new marine gravity data, collected on-board of a hydrographic survey vessel in and around West-Estonian Archipelago in 2016 .

The outline of the paper is as follows. First, theoretical principles of determining sea surface height and their use for validating geoid models are described. Theoretical background of processing kinematic GNSS data with precise point positioning solutions is also described briefly. The next sections give an overview of the methodology used during the marine gravity experiment and post-processing of GNSS and gravimetric data. Thereafter improvements in geoid modelling are examined and discussed. A brief summary concludes the paper.

\section{Theoretical principles}

\subsection{Determining sea surface heights, interrelations with geoid}

The position of the on-board antenna (most relevantly, the height) is determined by GNSS. At the moment of the GNSS measurement, instantaneous sea surface height $\left(\mathrm{SSH}_{i}\right)$ is obtained (accounting also for the separation between the GNSS antenna and vessel's waterline). Thus, if the height of the antenna with respect to sea surface is known, GNSS measurements provide instantaneous $\mathrm{SSH}_{i}$ reckoned from the surface of geodetic reference ellipsoid at a location with geodetic coordinates $\varphi, \lambda$ (Fig. 1):

$$
\operatorname{SSH}_{i}(\varphi, \lambda)=h_{i}(\varphi, \lambda)-R_{i}(\varphi, \lambda),
$$

where $h_{i}$ is the height of the GNSS antenna with respect to the reference ellipsoid (e.g. GRS-80) and $R_{i}$ is the range between the GNSS antenna and the sea surface (e.g. determined by tape measurements), both at the same time-instant $(i)$.

As the instantaneous sea surface height $\left(\mathrm{SSH}_{i}\right)$ is affected by tidal movement, wind direction and speed etc., then conventionally $S S H_{i}$ is referred to the mean sea level (MSL) by (cf. Fig. 1):

$$
\operatorname{MSL}(\varphi, \lambda)=S S H_{i}\left(\varphi_{i}, \lambda_{i}\right)-H_{i}\left(\varphi_{i}, \lambda_{i}\right),
$$

where $H_{i}$ is the sea level correction (e.g. estimated from nearby tide gauge (TG) station readings at the same time instant $i$, see e.g. a study by Liibusk et al. (2013); or using a suitable hydrodynamic model).

MSL is calculated from repeated measurements that are averaged over a certain time period (decades). MSL in open sea can be obtained by averaging satellite altimetry results and in coastal areas by averaging the TG time series. Historically, MSL at selected TG sites has been adopted as the "zero" level of national/local vertical datums.

On land high-precise GNSS-levelling points are customarily used to fit gravimetric geoid models $\left(N^{G G}\right)$

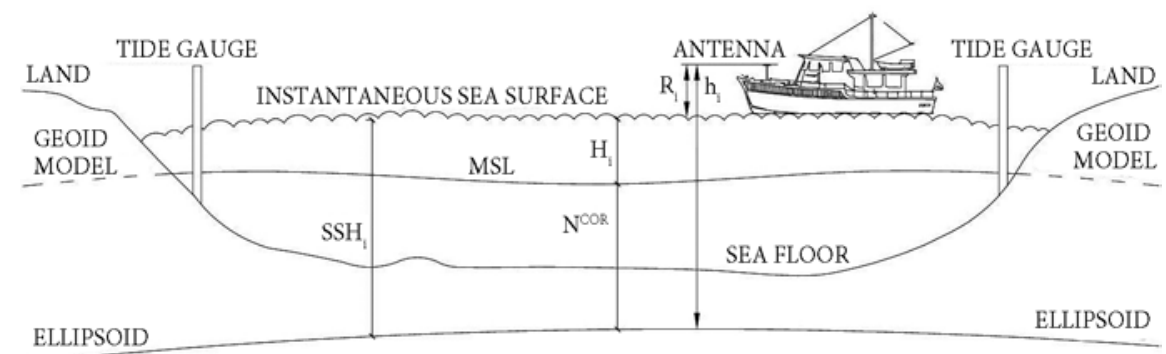

Fig. 1. Seaborne determination of sea surface heights (SSH) with respect to participating reference surfaces. The used symbols and abbreviations are explained in the text

Note: Figures have been generated using ArcGIS Desktop 10.5, Excel and GMT (Wessel et al. 2013) software. 
to the national vertical datum. For eliminating possible systematic biases a multi-parameter polynomial fit was often applied (see e.g. Ellmann $(2002,2005)$ and references therein) to achieve $1-3 \mathrm{~cm}$ post-fit accuracy for resulting height conversion surfaces in the past. Due to lack of such GNSS-levelling control data the height conversion surfaces $\left(N^{C O R}\right)$ over marine areas were obtained by extrapolation, i.e.:

$$
N^{C O R}(\varphi, \lambda)=N^{G G}(\varphi, \lambda)-H^{G G}(\varphi, \lambda),
$$

where the term $H^{G G}$ denotes the location dependent (polynomial) geoid correction term, i.e. the bias between the tested geoid model and the national vertical datum.

Certainly, the quality of the resulting height conversion surfaces remains dubious offshore. However, nowadays, as a result of the Nordic Geodetic Commission NKG2015 geoid modelling project (Ågren et al. 2015,2016 ) (which contain extensive data improvements, see e.g. Märdla et al. 2017) systematic biases in new geoid models over the region of interest have largely been eliminated. An important result is that the deviations from the new geoid models and national vertical datum can be eliminated by one-dimensional fit, i.e. in this case the term $H^{G G}$ in Eq. (3) appears to be a constant. This suggest also that the possible systematic biases in offshore have been reduced. Thus, the corrected geoid model $N^{C O R}$ approximately coincides with the vertical datum (based on the historical mean sea level determination):

$$
\operatorname{MSL}(\varphi, \lambda) \approx N^{C O R}(\varphi, \lambda) .
$$

We want to establish link between the geoid model and $\mathrm{SSH}_{i}$. Considering Eq. (2), then Eq. (4) becomes:

$$
N^{C O R}(\varphi, \lambda) \approx S S H_{i}\left(\varphi_{i}, \lambda_{i}\right)-H_{i}\left(\varphi_{i}, \lambda_{i}\right) .
$$

Note that the first term in the right-hand side is measured, whereas the second term need to be estimated by using a network of tide gauges or suitable hydrodynamic model.

Nowadays, different global or regional hydrodynamic models have been compiled by using oceanographic data, satellite altimetry or geodetic measurements. For example, the HIROMB (High Resolution Operational Model for the Baltic) or NEMO (Nucleus for European Modelling of the Ocean) are available over the Baltic Sea. The common disadvantage of these models is that their accuracy may often be poorer (especially in the coastal areas) than that of actual sea level observations. A note of warning on quality of TG readings is also due. Sometimes TG data may be unreliable or contaminated by systematic biases. Also, extrapolation from TG-s is needed in estimating $H_{i}$ for most of the offshore GNSS-profile points. In other words, in such a case the sea level correction would be a time-dependent quantity over the entire study area.

However, arguably the magnitude of formal inequality in Eq. (5) is numerically comparable with the uncertainties in GNSS measurements, in the term $H_{i}$ and geoid model to be validated. Therefore, in the present study we use a simplified geoid validation method, where the offshore $H_{i}$ will be estimated as a mean value $\bar{H}$ (within a time period of couple hours) between ship-borne GNSS-derived $\mathrm{SSH}_{i}$ and $\mathrm{N}^{\mathrm{COR}}$ of a geoid model being assessed. Thus, significant deviations from the mean (especially the one-sign ones, over a sequence of the route) may reveal errors in the tested geoid model. Comparing different concurrent geoid models enables determination of the best fit geoid model.

\subsection{GNSS precise point positioning}

Traditionally, costly commercial or sophisticated scientific software are used for post-processing ship-borne GNSS data. Instead, applicability of an alternative solution is tested in the present study. More specifically, recently easy-to-use online (PPP) services have become more popular as they give relatively good results (see, e.g. Ocalan et al. 2013).

PPP uses ionosphere-free combinations of dualfrequency GNSS pseudorange $(P)$ and carrier-phase observations $(\Phi)$ related to user position, clock, troposphere and ambiguity parameters according to the following simplified observation equations (Héroux, Kouba 2001):

$$
\begin{gathered}
P=\rho+C(d t-d T)+T_{r}+\varepsilon_{p} ; \\
\Phi=\rho+C(d t-d T)+T_{r}+N \lambda+\varepsilon_{\Phi},
\end{gathered}
$$

where: $P$ - ionosphere-free combination of L1 and L2 pseudoranges $\left(2.55 \mathrm{P}_{1}-1.55 \mathrm{P}_{2}\right) ; \Phi$ - ionosphere-free combination of L1 and L2 carrier-phases $\left(2.55 \Phi_{1}{ }^{-}\right.$ $\left.1.55 \Phi_{2}\right) ; \rho$ - geometrical range computed as a function of satellite and station coordinates; $C$ - vacuum speed of light; $d t$ - station clock offset from GNSS time; $d T$ satellite clock offset from GNSS time; $T_{r}$ - signal path delay due to the neutral-atmosphere; $\lambda$ - carrier, or carrier-combination, wavelength; $N$ - ambiguity of the carrier-phase ionosphere-free combination; $\varepsilon_{p}, \varepsilon_{\Phi}-$ relevant measurement noise components, including multipath. 
Then the GNSS antennae 3D positions are computed with respect to GNSS-CORS (Continuously Operating Reference Station) stations. The online-PPP services usually rely upon a limited number of internationally recognized GNSS-CORS rather than using nearby national/commercial ones. For this study, several innovative online-PPP services were tested, the corresponding results were compared to the results obtained by traditional algorithms as adopted in many commercial software and with respect to nearby located national GNSS-CORS.

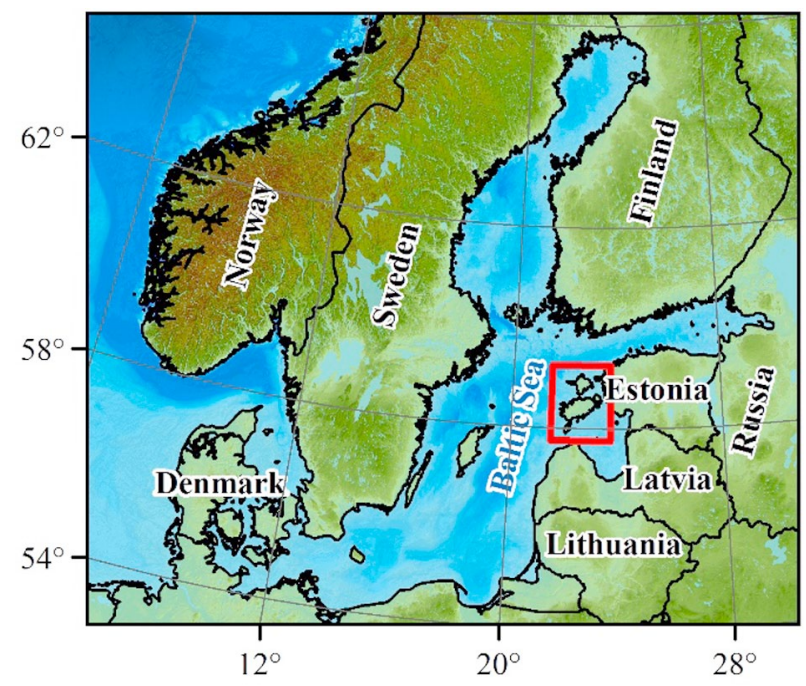

Fig. 2. Baltic Sea and the surrounding countries. The location of the study area is marked on the map by the red rectangle

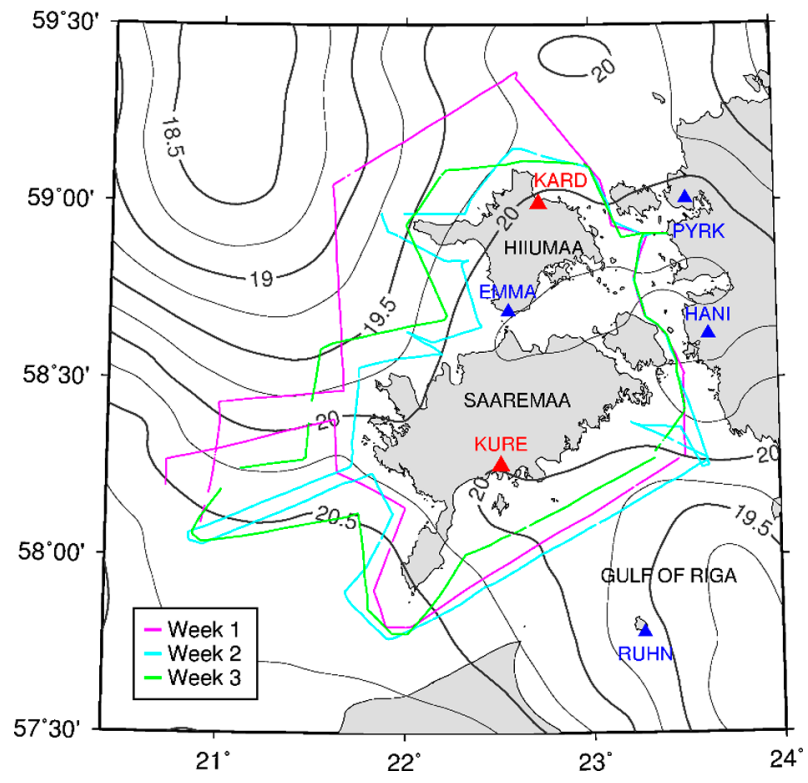

Fig. 3. Transit routes of the survey vessel and the used GNSS-CORS stations (denoted by colored triangles and 4-letter abbreviations) in West-Estonian Archipelago. The isolines depict the NKG2015 quasigeoid model in the study area. Units in metres

\section{Study area, data acquisition and geoid models}

A marine gravity experiment was carried out on board the Estonian Maritime Administration survey vessel "Jakob Prei" (JP) between 27.06.2016 and 15.07.2016. The vessel was deployed for hydrographic surveys over large areas West of Saaremaa in the central part of the Baltic Proper and the Gulf of Riga, cf. Figures 2 and 3.

However, our current research interest focuses mostly in transit routes, which were conducted around the islands of Saaremaa and Hiiumaa in West-Estonian archipelago (Fig. 3). The ship was offshore on all three weeks from Monday to Friday, returning to the base harbour for week-ends.

Gravimetric data were also gathered by using a Russian Elektropribor manufactured marine gravimeter Chekan-AM that was mounted by the Danish Technical University (DTU) team. The gravity survey post-processing revealed a precision better than $1 \mathrm{mGal}$ (Olesen, Kasenda 2016).

Additionally, a standard Javad GNSS antenna was attached to the starboard of ship's railing. A dual frequency Javad Delta GPS/GLONASS receiver was used to collect GNSS data for profiles. The GNSS receiver sampled the 3D position with a 5 second interval $(1 / 5 \mathrm{~Hz})$ constantly from 24.06 .2016 to 15.07 .2016 into sequential $24 \mathrm{~h}$ long data files. The same interval data were also received from six Estonian GNSS-CORS (see Fig. 3) over the same time period. These data were later used for precise post-processing the vessel's routes and for evaluating geoid models.

Three marine geoid models to be assessed by ship-borne GNSS profiles are as follows: (i) The official NKG2015 quasigeoid model released by the Nordic Geodetic Commission (NKG), see Ågren et al. (2016) for further details; (ii) Model 1 - a preliminary NKG2015 quasigeoid model computed at Tallinn University of Technology (TTÜ) in 2016; (iii) Model 2 - another preliminary quasigeoid model computed similarly to Model 1, but including the newly acquired marine gravity data. Note that the two first models do not contain the gravimetric data collected during the marine gravity experiment. However, all known systematic biases in terrestrial gravity data (see e.g. Ellmann et al. 2009) have been removed from the NKG gravity database prior the computations. The resulting geoid models were evaluated by the Estonian high-precision GNSS-levelling control points, yielding a sub-centimetre accuracy (in terms of StDev). For more details see Märdla et al. (2017). 
Models 1 and 2 have been computed similarly to the NKG2015 geoid model, i.e. by using Least Squares Modification of Stokes' formula (e.g. Sjöberg 2003) and the GO_CONS_GCF_2_DIR_R5 (Bruinsma et al. 2014) global geopotential model as the reference surface. All the models have a spatial resolution of $0.01 \times 0.02$ arc-deg (approximately $1.1 \times 1.1 \mathrm{~km}$ within the study area). The gravity data, the applied gridding strategies and quality assurance methods are explained in Märdla et al. (2017).

\section{The GNSS results}

The data processing revealed multiple gaps in GNSS data-series (e.g. see Fig. 4 from 20:58 to 21:19). Some of these lasted over 10 minutes, corresponding up to ca $3.5 \mathrm{~km}$ in transit routes. The likely reason is malfunctioning of the used GNSS receiver.

Two different commercial software were used for post-processing kinematic GNSS data-series. These were Trimble Business Centre ${ }^{\mathrm{mm}}$ v3.80 (TBC) and NovAtel Inertial Explorer $^{\text {mo }}$ v8.60 (IE). Considering the standard deviation of the profiles (such a comparison is not shown here) and visual evaluation of processed GNSS data, more accurate results were obtained with TBC.

Alternatively, several online-PPP services were tested: APPS (n.d.), GAPS (n.d.), magicGNSS (n.d.) and CSRS-PPP (n.d.). As the Canadian CSRS-PPP was the most convenient for current data processing needs (in contrast, the $24 \mathrm{~h}$ data files appeared to be too large for APPS) and the quality of the results was sufficient for comparison with that of the commercial software, it was selected for this study. CSRS-PPP uses precise GPS orbit and clock products provided by IGS (International GNSS Service) and Natural Resources
Canada (NRCan), whereas it estimates single station positions in static and kinematic modes (Ocalan et al. 2013). The CSRS-PPP position estimations are computed from code pseudorange $(P)$ or carrier-phase $(\Phi)$ observations of the used dual frequency GNSS rover receiver. The CSRS-PPP results were then compared to those of the TBC commercial software.

The global ITRF datum was selected for kinematic processing of CSRS-PPP. The PPP service does not reveal the used GNSS-CORS reference stations, though. It appeared that when the $24 \mathrm{~h}$ long data files were processed the PPP service gives statistically better results (as compared to commercial software) on long (extending several hundred kilometres) transit routes. Yet, it emerged that the TBC calculations are more accurate with respect to the nearest national GNSS-CORS station. An example of differences between the results of two software on a long transit route after low-pass filtering GNSS data (to be discussed later) can be seen in Figure 4. The ship was the closest to the reference stations within 12:40 and 18:10, whereas the furthest at the end of the day. Statistical differences between CSRS-PPP and TBC data processing with respect to the official NKG2015 geoid model can be seen in a table below. Due to better performance, the TBC was chosen as final data processing software for this study.

The daily GNSS data-files were cut into several sequences in a way that each single kinematic point was calculated with respect to the closest national CORS station (see Fig. 3). Precise IGS (SP3 format) ephemerides were used for the calculations. A priori error estimate as of $0.200 \mathrm{~m}+1.0 \mathrm{ppm}$ was adopted to process the vertical component of the GNSS data. Calculation results exceeding this limiting value were excluded. Discrepancies between height computations from adjacent base stations were insignificant compared to the

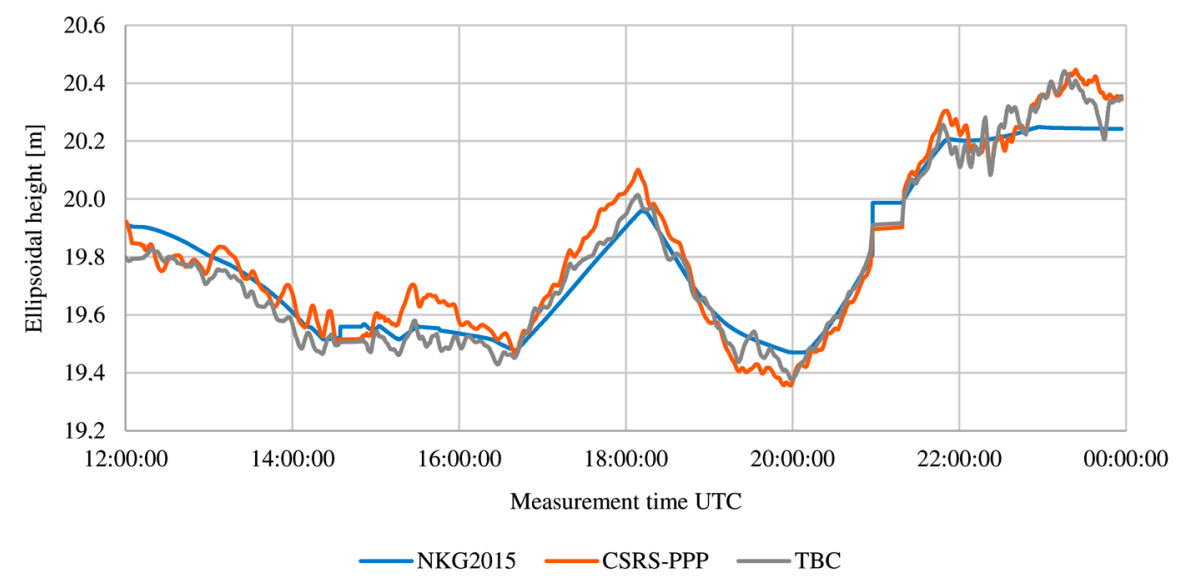

Fig. 4. CSRS-PPP and TBC calculations after filtering the GNSS-results (see below), as compared to the NKG2015 geoid model profile (after removal of the 1-dimensional offset $\bar{H}$ from filtered data) 
up-down movement of the ship. After processing all GNSS data in this way (both fixed and float solutions were aimed at), the results were recompiled into $24 \mathrm{~h}$ long files.

A double low-pass filtering was applied for reducing the sea wave effect in GNSS data. Considering the average moving speed of the ship on transit routes, a moving median of 39 measurements was first taken:

$$
\tilde{h}(i)=\operatorname{median}\left(h_{i}[i-19, i+19]\right) \text {, }
$$

where $h_{i}$ (blue line in Fig. 5) is a GNSS height component at time instant $i$ and $\tilde{h}$ (purple line in Fig. 5) median value of it in the range of the filter, i.e. the interval from 19 epochs before time instant $i$ up to 19 epochs after the time instant $i .39$ measurements (195 s) were chosen for the filtering window as this corresponds in length to the spatial resolution of the tested geoid models, which is about $1 \mathrm{~km}$. Taking a median allowed to eliminate standalone gross errors in TBC calculations, as well as gross errors in GNSS measurements. From that outcome, a moving average of 39 measurements was also taken:

$$
h^{f}(i)=\frac{1}{39} \sum_{n=i-19}^{i+19} \tilde{h}(n),
$$

where $h^{f}$ (orange line in Fig. 5) is low-pass filtered GNSS measurement at time instant $i$. Average was taken to further smoothen GNSS data. In the smoothing process of the $24 \mathrm{~h}$ files the data from adjacent days were included as well.

In order to see how filtered GNSS data compares to geoid model with its spatial resolution (to find out if dense data points improve or worsen the results), further average of 39 was taken from low-pass filtering result:

$$
h^{a}(j)=\frac{1}{39} \sum_{n=i-19}^{i+19} h^{f}(n) \text {, }
$$

where $h^{a}$ (green line in Fig. 5) is averaged low-pass filtering result for a time period $j$ (lasting $195 \mathrm{~s}$, corresponding approximately to $1 \mathrm{~km}$ route). Note that unlike the Eq. (9), the average in Eq. (10) is not a moving one. Such a double low-pass and further averaged filtering scheme is visualised in Figure 5. The orange and green results in Figure 5 to be used for validating the participating geoid models.

Although the results coincide with geoid models, this method does not eliminate long-wavelength errors in TBC calculations (see a sample in Figure 7 from the time 5:24 to 5:29). Similar errors are seen in other software solutions, be it online-PPP services or the IE. However, spatial locations of these errors do not coincide for different software solutions.

As only one GNSS antenna was used, regrettably thus errors from the ship's attitude (roll and pitch) cannot be estimated. There is no need to know the antenna height $\left(R_{i}\right)$ as only relative change of sea level surface is determined (see Eq. 1). As the ship's water-line is regulated with ballast water synchronously with the fuel consumption, there is no need for such a correction after refuelling either. Rigorously, the non-constant sea surface topography (SST) should also be considered, however, this was neglected in the current (tentative) study for the sake of simplification. It is expected that accounting for the SST could yield certain improvements in our further studies.

\section{Comparison of GNSS profiles with geoid models}

The most affected area by new gravimetric data lies West of Saaremaa where differences between the geoid Model 1 and Model 2 are the largest (Model 2 being generally lower than Model 1, Fig. 6). The GNSS profiles within that area (Table 1 ) are statistically analysed in Table 3 and Figure 7.

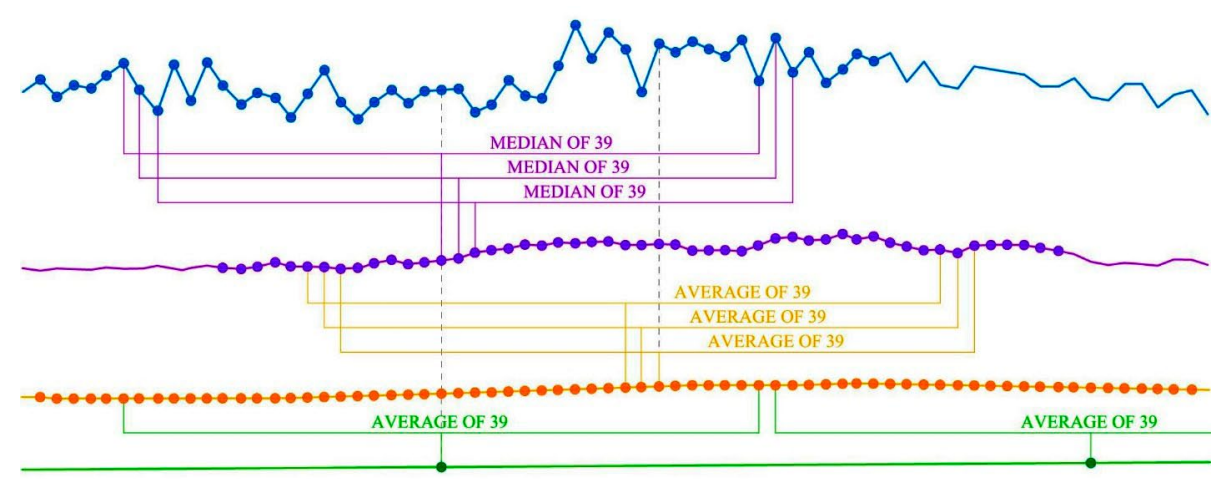

Fig. 5. Methodology of double low-pass and further averaged filtering of GNSS data (blue - raw GNSS result $h_{i}$; purple - median values of raw GNSS result $\tilde{h}$; orange - low-pass filtering result $h^{f}$; green - averaged low-pass filtering result $h^{a}$ ) 
StDev of averaged low-pass filtering result is lower than StDev of the initial filtering result (see Tables 2 and 3), because averaging (see Fig. 5) eliminates remaining larger fluctuations from filtered data when compared to geoid models.

Note that statistics of profile (2) do not coincide in Table 2 (TBC) and Table 3 (NKG2015). This is because some of the measurements calculated by TBC were excluded by CSRS-PPP (or vice versa) and therefore the amount of processed data points differs between two

Table 1. General statistics of the GNSS profiles

\begin{tabular}{|c|c|c|c|c|}
\hline $\begin{array}{c}\text { Profile } \\
\text { number }\end{array}$ & $\begin{array}{c}\text { Measu- } \\
\text { rement } \\
\text { time }\end{array}$ & $\begin{array}{c}\text { Profile } \\
\text { length } \\
(\mathrm{km})\end{array}$ & $\begin{array}{c}\text { Number of } \\
\text { low-pass } \\
\text { filtering } \\
\text { results }\end{array}$ & $\begin{array}{c}\text { Number } \\
\text { of further } \\
\text { averaged } \\
\text { results }\end{array}$ \\
\hline$(1)$ & 28.06 .2016 & 66.6 & 2243 & 58 \\
\hline$(2)$ & 30.06 .2016 & 118.8 & 3807 & 98 \\
\hline$(3)$ & 05.07 .2016 & 60.7 & 2052 & 53 \\
\hline$(4)$ & 11.07 .2016 & 95.6 & 3097 & 79 \\
\hline
\end{tabular}

processing software. Only temporally coinciding measurements were considered for comparisons.

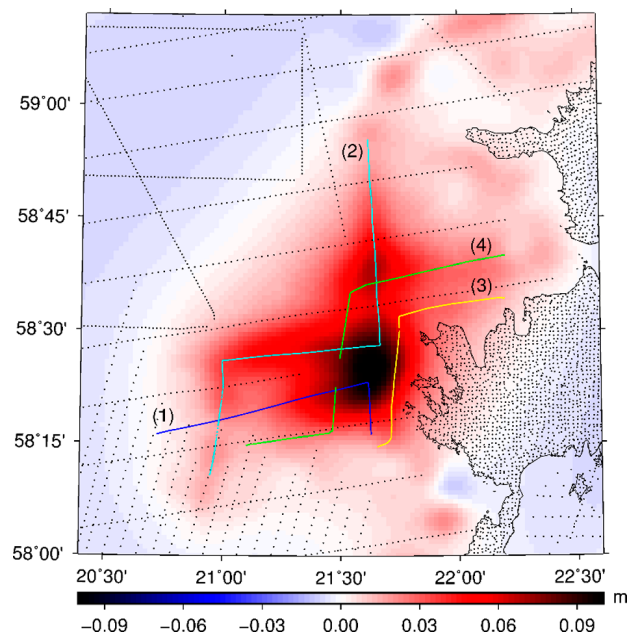

Fig. 6. Location of GNSS profiles within the area of the largest geoid model change gradient due to the newly collected JP gravity data. The black dots indicate the locations of previously existing gravity data available for the geoid modelling. The red tones denote the areas where Model 2 is lower than Model 1

Table 2. Statistics of differences between GNSS calculations using either TBC or CSRS-PPP compared to official NKG2015 geoid model

\begin{tabular}{|c|c|c|c|c|c|c|}
\hline Software & Profile number & Mean $(\mathrm{m})^{1}$ & Min $(\mathrm{m})^{2}$ & Max $(\mathrm{m})^{2}$ & StDev $(\mathbf{m})$ & Further averaged StDev $(\mathbf{m})$ \\
\hline & $(1)$ & 5.905 & -0.280 & 0.228 & $\mathbf{0 . 1 2 0}$ & $\mathbf{0 . 1 1 6}$ \\
TBC & $(2)$ & 6.012 & -0.112 & 0.252 & $\mathbf{0 . 0 4 9}$ & $\mathbf{0 . 0 4 8}$ \\
& $(3)$ & 6.112 & -0.150 & 0.136 & $\mathbf{0 . 0 5 3}$ & $\mathbf{0 . 0 5 2}$ \\
& $(4)$ & 6.223 & -0.115 & 0.111 & $\mathbf{0 . 0 4 2}$ & $\mathbf{0 . 0 3 9}$ \\
CSRS-PPP & $(1)$ & 5.957 & -0.098 & 0.099 & $\mathbf{0 . 0 5 3}$ & $\mathbf{0 . 0 5 2}$ \\
& $(2)$ & 5.973 & -0.121 & 0.110 & $\mathbf{0 . 0 5 5}$ & $\mathbf{0 . 0 5 4}$ \\
& $(3)$ & 6.126 & -0.127 & 0.110 & $\mathbf{0 . 0 4 7}$ & $\mathbf{0 . 0 4 6}$ \\
\hline
\end{tabular}

Notes: Statistics of the profile (4) analysed in Figure 3 (from 18:00 to 23:00) are high-lighted in red (see also Fig. 6 and Table 1).

${ }^{1}$ Mean difference between the low-pass filtered GNSS measurements and geoid height. GNSS antennae was approximately $6 \mathrm{~m}$ above sea suface.

${ }^{2}$ After removal of the mean difference between low-pass filtered GNSS measurements and geoid height (third column).

Table 3. Statistics of differences between GNSS measurements and geoid models within the area of the largest geoid model change gradient

\begin{tabular}{|c|c|c|c|c|c|c|}
\hline Geoid model & Profile number & Mean $(\mathrm{m})^{1}$ & Min $(\mathrm{m})^{2}$ & Max $(\mathrm{m})^{2}$ & StDev $(\mathbf{m})$ & Further averaged StDev $(\mathbf{m})$ \\
\hline & $(1)$ & 5.905 & -0.280 & 0.228 & $\mathbf{0 . 1 2 0}$ & $\mathbf{0 . 1 1 6}$ \\
NKG2015 & $(2)$ & 6.015 & -0.115 & 0.267 & $\mathbf{0 . 0 5 6}$ & $\mathbf{0 . 0 5 5}$ \\
& $(3)$ & 6.112 & -0.150 & 0.136 & $\mathbf{0 . 0 5 3}$ & $\mathbf{0 . 0 5 2}$ \\
& $(4)$ & 6.223 & -0.115 & 0.111 & $\mathbf{0 . 0 4 2}$ & $\mathbf{0 . 0 3 9}$ \\
\hline \multirow{3}{*}{ Model 1 } & $(1)$ & 5.309 & -0.281 & 0.226 & $\mathbf{0 . 1 2 0}$ & $\mathbf{0 . 1 1 6}$ \\
& $(2)$ & 5.418 & -0.117 & 0.267 & $\mathbf{0 . 0 5 7}$ & $\mathbf{0 . 0 5 6}$ \\
& $(3)$ & 5.514 & -0.148 & 0.134 & $\mathbf{0 . 0 5 1}$ & $\mathbf{0 . 0 5 1}$ \\
& $(4)$ & 5.624 & -0.113 & 0.113 & $\mathbf{0 . 0 4 2}$ & $\mathbf{0 . 0 3 9}$ \\
\hline & $(1)$ & 5.353 & -0.207 & 0.207 & $\mathbf{0 . 1 0 9}$ & $\mathbf{0 . 1 0 4}$ \\
& $(2)$ & 5.466 & -0.103 & 0.269 & $\mathbf{0 . 0 6 1}$ & $\mathbf{0 . 0 6 0}$ \\
& $(3)$ & 5.558 & -0.122 & 0.113 & $\mathbf{0 . 0 4 2}$ & $\mathbf{0 . 0 4 1}$ \\
\hline
\end{tabular}

Note: Statistics of the profile (3) analysed in Figure 6 are high-lighted in red (see also Fig. 6 and Table 1). 


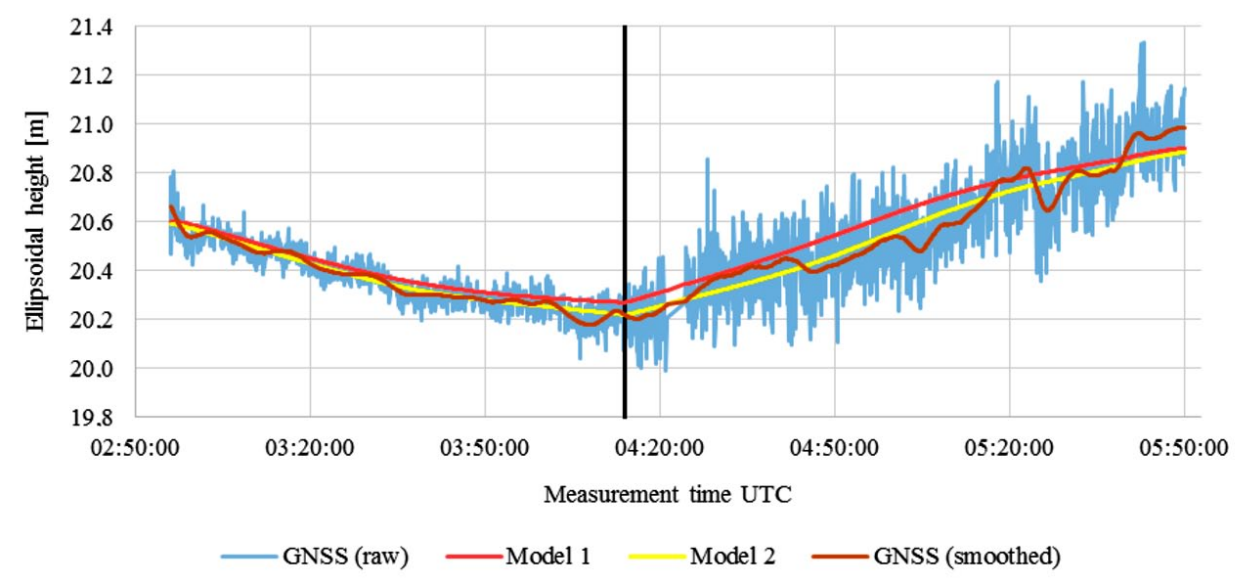

Fig. 7. An example of GNSS profile (3) compared to Model 1 and 2 geoid models (after removal of 1-dimensional offset $\bar{H}$ ). The vertical black line at 4:13 indicates the turning point of the vessel. The increase of measurements amplitude after the turnpoint illustrates the effect of measurement conditons (rougher waters, most likely) on the GNSS results

As seen from Table 3, Model 1 is comparable in precision to the official NKG2015 geoid model. However, the precision of Model 2 (with the new gravimetric data collected on "Jakob Prei" during the experiment), with respect to the GNSS data, has improved at places (see Fig. 7). The largest improvement in the geoid model occurs in offshore areas with poor coverage of g-data points (see Fig. 6).

\section{Conclusions}

Ship-borne GNSS profiles prove to be an effective method to evaluate existing concurrent geoid models. For this, it is important to achieve precise GNSS height data. In the absence of close reference stations, online-PPP services are an option as they give sufficient precision for further data processing and are easy to use, requiring no previous experience in GNSS data processing.

During the study it became evident that appropriate smoothing of GNSS data is essential to assess the geoid models. It is also expected that accounting for the sea surface topography at GNSS profiles would improve the results, as well as using more than one GNSS antenna to remove errors from ships attitude.

The GNSS height profiles were used to evaluate geoid models West of Saaremaa, where the gravity data collected during the "Jakob Prei" campaign had the largest effect on the resulting geoid model. It was found that the model computed using the newly acquired gravity data agree better with the GNSS profiles.

This study can be considered as preparation for the planned marine gravity project to be carried out at the eastern end of Gulf of Finland (Narva Bay) in summer of 2017. The lessons learned will be considered at elaborating methodology for densifying gravimetric data there and along the North-Estonian shores. Note also that instantaneous marine dynamic topography (e.g. occurring due to coastal currents and/or unidirectional wind) was neglected in the present exercise. For further studies, the Estonia adapted (by the Marine Systems Institute of TTÜ) sea surface topography model HIROMB-EST (for more details see Lagemaa 2012), will be tested.

\section{Acknowledgements}

This study was conducted within the frames of a Connecting Europe Facility (CEF) project "FAMOS (Finalising Surveys for the Baltic Motorways of the Sea) Odin" (VEU16013). The Estonian Maritime Agency is acknowledged for providing the hydrographic survey vessel "Jakob Prei" for the 2016 marine gravity campaign. R. Forsberg, A. V. Olesen and F. Kasenda of Danish Technical University are thanked for providing the GNSS-data and the processed gravimetric data. K. Kollo of the Estonian Land Board provided the GNSS-CORS data.

\section{References}

Ågren, J.; Strykowski, G.; Bilker-Koivula, M.; Omang, O.; Märdla, S.; Oja, T.; Liepinš, I.; Paršeliūnas, E.; Forsberg, R.; Kaminskis, J.; Ellmann, A.; Sjöberg, L.; Valsson, V. 2015. On the development of the new Nordic gravimetric geoid model NKG2015, in 26th IUGG General Assembly, 22 June - 2 July 2015, Prague, Czech Republic.

Ågren, J.; Strykowski, G.; Bilker-Koivula, M.; Omang, O.; Märdla, S.; Forsberg, R.; Ellmann, A.; Oja, T.; Liepinš, I.; Paršeliūnas, E.; Kaminskis, J.; Sjöberg, L.; Valsson, G. 2016. The NKG2015 gravimetric geoid model for the Nordic-Baltic region, in 1st Joint Commission 2 and IGFS Meeting International Symposium on Gravity, Geoid and Height Systems, 19-23 September 2016, Thessaloniki, Greece. 
APPS [online]. n.d. [cited 18 January 2017]. Available from Internet: http://apps.gdgps.net/

Bruinsma, S. L.; Förste, C.; Abrikosov, O.; Lemoine, J.-M.; Marty, J.-C.; Mulet, S.; Rio, M.-H.; Bonvalot, S. 2014. ESA's satellite-only gravity field model via the direct approach based on all GOCE data, Geophysical Research Letters 41(21): 7508-7514. https://doi.org/10.1002/2014GL062045

CSRS-PPP [online]. n.d. [cited 18 January 2017]. Available from Internet: https://webapp.geod.nrcan.gc.ca/geod/tools-outils/ ppp.php

Ellmann, A. 2002. An improved gravity anomaly grid and a geoid model for Estonia, Proceedings of Estonian Academic Sciences, Geology 51: 199-214.

Ellmann, A. 2005. Two deterministic and three stochastic modifications of Stokes's formula: a case study for the Baltic countries, Journal of Geodesy 79: 11-23.

https://doi.org/10.1007/s00190-005-0438-1

Ellmann, A.; All, T.; Oja, T. 2009. Toward unification of terrestrial gravity datasets in Estonia, Estonian Journal of Earth Sciences 58(4): 229-245.

https://doi.org/10.3176/earth.2009.4.02

Ellmann, A. 2010. Validation of the new Earth Gravitational Model EGM08 over the Baltic countries, International Association of Geodesy Symposia 135: 489-496. https://doi.org/10.1007/978-3-642-10634-7_65

FAMOS. 2017. Finalising surveys for the Baltic Motorways of the Sea webpage. [online], [cited 12 January 2017]. Available from Internet: http://www.famosproject.eu/famos/

Forsberg, R.; Strykowski, G.; Solheim, D.; 2004. NKG-2004 geoid of the Nordic and Baltic Area, in Proceedings of the IAG International Symposium "Gravity, Geoid and Satellite Gravity Missions", 30 August - 3 September 2004, Porto, Portugal. CD-ROM.

GAPS [online]. n.d. [cited 18 January 2017]. Available from Internet: http://gaps.gge.unb.ca/

Gruno, A.; Liibusk, A.; Ellmann, A.; Oja, T.; Vain, A.; Jürgenson, H. 2013. Determining sea surface heights using small footprint airborne laser scanning, in Proceedings SPIE 8888, Remote Sensing of the Ocean, Sea Ice, Coastal Waters, and Large Water Regions 2013, 23 September 2013, Dresden, Germany. International Society for Optical Engineering, 88880R1-88880R13. https://doi.org/10.1117/12.2029189

Héroux, P.; Kouba, J. 2001. GPS Precise Point positioning using IGS orbit products, Physics and Chemistry of the Earth, Part A: Solid Earth and Geodesy 26(6-8): 573-578. https://doi.org/10.1016/S1464-1895(01)00103-X

Jürgenson, H.; Liibusk, A.; Ellmann, A. 2008. Geoid profiles in the Baltic Sea determined using GPS and sea level surface, Geodezija Ir Kartografia / Geodesy and Cartography 34(4): 109-115.

Lagemaa, P. 2012. Operational forecasting in Estonian marine waters: PhD thesis. Tallinn University of Technology, Tallinn.

Lavrov, D.; Even-Tzur, G.; Reinking, J. 2016. Expansion and improvement of the Israeli geoid model by ship-borne GNSS measurements, Journal of Surveying Engineering 143(2). https://doi.org/10.1061/(ASCE)SU.1943-5428.0000204

Liibusk, A.; Ellmann, A. 2015. Validation of marine geoid models by profile-wise GNSS measurements on ice surface, $\mathrm{Ma}$ rine Geodesy 38(4): 314-326. https://doi.org/10.1080/01490419.2015.1037408

Liibusk, A.; Talvik, S.; Ellmann, A.; Oja, T. 2014. Determining regional sea surface topography by GNSS surveys on ice, in 6th IEEE/OES Baltic Symposium 2014 "Measuring and Modeling of Multi-Scale Interactions in the Marine Environment", 26-29 May 2014, Tallinn, Estonia. IEEE, 1-8. https://doi.org/10.1109/BALTIC.2014.6887847

Liibusk, A.; Ellmann. A.; Kõuts, T.; Jürgenson, H. 2013. Precise Hydrodynamic Levelling by Using Pressure Gauges, Marine Geodesy 36(2): 138-163.

https://doi.org/10.1080/01490419.2013.771594

MagicGNSS [online]. n.d. [cited 18 January 2017]. Available from Internet: https://magicgnss.gmv.com/

Märdla, S.; Ågren, J.; Strykowski, G.; Oja, T.; Ellmann, A.; Forsberg, R.; Bilker-Koivula, M.; Omang, O.; Paršeliūnas, E.; Liepinš, I.; Kaminskis, J. 2017. From discrete gravity survey data to a high-resolution gravity field representation in the Nordic-Baltic region, Marine Geodesy 40, (advance online publication). https://doi.org/10.1080/01490419.2017.1326428

Märdla, S.; Oja, T.; Ellmann, A.; Jürgenson, H. 2015. Improving and validating gravity data over ice-covered marine areas, in C. Rizos, P. Willis (Eds.). IAG 150 Years. International Association of Geodesy Symposia, Vol. 143. Springer, 263-270. https://doi.org/10.1007/1345_2015_163

Ocalan, T.; Erdogan, B.; Tunalioglu, N. 2013. Analysis of webbased online services for GPS relative and precise point positioning techniques, Boletim de Ciencias Geodesicas 19(2): 191-207. https://doi.org/10.1590/S1982-21702013000200003

Olesen, A. V.; Kasenda, F. 2016. Marine gravity onboard Jakob Prey June/July 2016, processing report. Danish Technical University (DTU).

Sjöberg, L. E. 2003. A computational scheme to model the geoid by the modified Stokes formula without gravity reductions, Journal of Geodesy 77(7): 423-432. https://doi.org/10.1007/s00190-003-0338-1

Wessel, P.; Smith, W. H. F.; Scharroo, R.; Luis, J.; Wobbe, F. 2013. Generic mapping tools: improved version released, Eos, Transactions American Geophysical Union 94(45): 409-410. https://doi.org/10.1002/2013EO450001

Sander VARBLA, master's student, Tallinn University of Technology, Department of Civil Engineering and Architecture, Road Engineering and Geodesy Research Group.

Artu ELLMANN received his MSc degree in geodesy from the Moscow State University of Geodesy and Cartography (formerly MIIGAiK) in 1993 and a $\mathrm{PhD}$ degree from the Royal Institute of Technology (KTH) in Stockholm in 2004. He is currently Professor in Geodesy at the Department of Civil Engineering and Architecture, School of Engineering at the TTÜ. National correspondent to the International Association of Geodesy (IAG) since 2006. His research interests include physical geodesy (gravity field and geoid modelling in particular) and remote sensing applications for engineering surveying.

Silja MÄRDLA received her MSc degree in geodesy from TTÜ, currently she is a $\mathrm{PhD}$ candidate and research scientist at Tallinn University of Technology focusing on gravity field and geoid modelling studies. She has also studied construction geodesy and terrestrial laser scanning related problems.

Anti GRUNO, received his MSc degree in geodesy from TTÜ, currently working Estonian Land Board Photogrammetry Department. Main task is Airborne Lidar scanning data processing. 